\title{
AS POLÍTICAS DE ASSISTÊNCIA ESTUDANTIL EM UMA UNIVERSIDADE FEDERAL BRASILEIRA: ANÁLISE DAS POLÍTICAS PREVISTAS NO PNAES
}

\author{
Luciléia Bechmann Saldanha \\ Acadêmica do Curso de Licenciatura em Educação Especial/Noturno. \\ Universidade Federal de Santa Maria - UFSM. \\ E-mail: luh.bechmann@hotmail.com
}

Sabrina Fernandes de Castro

Professora do Departamento de Educação Especial/Centro de Educação e da Pós-Graduação em Educação Profissional e Tecnológica na Universidade Federal de Santa Maria - UFSM.

E-mail:sabrinafcastro@gmail.com

\begin{abstract}
RESUMO
A pesquisa ora apresentada teve como objetivo principal averiguar os diferentes tipos de políticas de assistência estudantil existentes dentro de uma Universidade Federal localizada ao Sul do País. Os participantes desta investigação foram estudantes de graduação de cursos presenciais, de um centro de ensino, da referida Universidade. Trata-se de um estudo de caso de caráter qualitativo. Em virtude do isolamento social, ocasionado pela pandemia da COVID-19, a investigação se desenvolveu de forma remota, onde os dados foram coletados através da Plataforma Google Forms composto por 14 perguntas, divididas em duas categorias: perfil dos participantes e assistência estudantil. Foi encaminhado uma carta convite para as cinco coordenações dos cursos do Centro investigado, ao final, obteve-se a participação de 45 estudantes, de quatro diferentes cursos. Entre os principais resultados, destacam-se que $97 \%$ eram do sexo feminino; $54 \%$ dos participantes ingressaram na Universidade através de ampla concorrência; 74\% utilizavam algum dos meios de assistência estudantil descritos pelo PNAES, sendo a alimentação a mais utilizada. Diante do exposto, foi possível inferir sobre a importância da efetivação e divulgação das políticas existentes, visto que $20 \%$ disseram não saber o que eram políticas de ações afirmativas e 13\% não sabiam se já tinham utilizado algum meio de assistência estudantil. Reafirma-se a importância de continuar com investigações que acompanhem o desenvolvimento dessas políticas, bem como se faz importante a manutenção dos recursos governamentais compatíveis a demanda e a ampla divulgação das ações implementadas.
\end{abstract}

Palavras-chave: Assistência Estudantil. PNAES. Ensino Superior. Inclusão.

\section{INTRODUÇÃO}

Os resultados ora apresentados compõem uma pesquisa maior intitulado "As políticas de ações afirmativas na perspectiva dos acadêmicos de um centro de ensino de uma Universidade Federal" que objetivava averiguar os diferentes tipos de políticas de assistência estudantil existentes dentro de uma Universidade Federal, focando em questões relativas à acessibilidade e políticas para inclusão de estudantes com deficiência e em situação de vulnerabilidade socioeconômica. 
Assim, nesse artigo apresentamos uma breve discussão a respeito das políticas de ações afirmativas para estudantes em situação de vulnerabilidade socioeconômica no Ensino Superior, partindo da realidade de discentes de uma universidade pública federal. Tal discussão, mesmo não focando na proposta central do dossiê, é entendida por nós como relevante para ampla divulgação, visto que tais ações vem garantindo o ingresso e permanências de muitos estudantes nas universidades Brasil afora.

Deste modo, partimos do conceito de inclusão descrito por Booth e Ainscow ${ }^{1}$ (2002, p. 9.) que estende para além das pessoas com deficiência:

[...] a inclusão está relacionada a qualquer tipo de discriminação e exclusão, pois entende-se que há muitos estudantes que não possuem a mesma igualdade de oportunidades educativas e nem recebem uma educação adequada às suas necessidades e características pessoais

Entendemos, assim que a inclusão se destina a distintas minorias, aproximando e objetivando a equidade para o ingresso, mas principalmente, para a permanência e formação adequada.

O Governo brasileiro, entre 2010 e 2016, instituiu políticas de assistência estudantil e ações afirmativas que visam o acesso e a permanência de estudantes em Instituições Federais de Ensino Superior (IFES).

As ações afirmativas, segundo o Ministério da Educação, são "o conjunto de medidas especiais voltadas a grupos discriminados e vitimados pela exclusão social ocorridos no passado ou no presente" (BRASIL, 2020). Entre as quais estão: pessoas pretas e pardas; indígenas e quilombolas; e, também fazem parte desse grupo, às pessoas com deficiência, mesmo que comumente não esteja relacionado nas pesquisas.

Já à assistência estudantil são programas que tem como objetivo principal a viabilização da permanência e inserção de forma efetiva no ensino superior (VARGAS; HERINGER. 2017) para os estudantes pertencentes a grupos discriminados.

Assim, as ações afirmativas "visam cumprir uma finalidade pública e decisiva para o projeto democrático, que é a igualdade de direitos, apesar da diversidade e da pluralidade social" (FALCÃO et al., 2008).

Entre as políticas instituídas, destacam-se: o Decreto 7.234/2010, de 19 de julho de 2010, e a Lei 12.711/2012, de 29 de agosto de 2012.

\footnotetext{
${ }^{1}$ Tradução livre das autoras do presente artigo.
} 
O Decreto 7.234/2010, cria o Programa Nacional de Assistência Estudantil (PNAES) (BRASIL, 2010) visando garantias de condições básicas de vida para os estudantes de baixa renda, como:

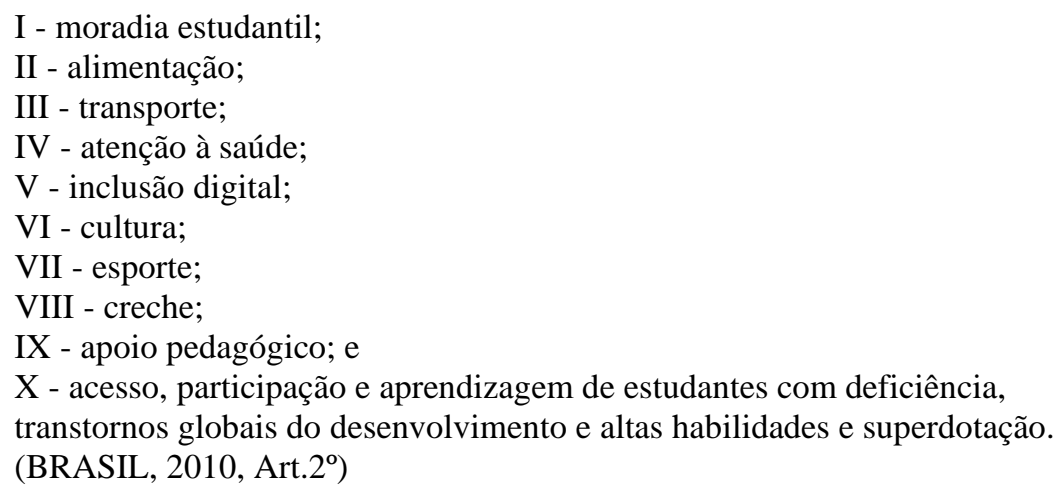

E a Lei 12.711/2012, a popular "Lei de Cotas" (BRASIL, 2012) que prevê a reserva de vagas para grupos considerados minoritários, como: estudantes que tenham cursado integralmente o ensino médio em escolas públicas; estudantes oriundos de famílias com renda igual ou inferior a 1,5 salário-mínimo per capita; estudantes autodeclarados pretos, pardos ou indígenas. Posteriormente, os estudantes com deficiência foram inseridos como um dos grupos minoritários, através da Lei 13.409/2016, de 28 de dezembro de 2016 (BRASIL, 2016).

Com a Lei de Cotas (BRASIL, 2012) houve a ampliação do PNAES, pois sucedeu um avanço na democratização do acesso de pessoas em situação de vulnerabilidade social e oriundos de escola pública (MATTOS; FERNANDES. 2019). As autoras ainda referenciam os trabalhos de Ristoff (2014); Silva e Fernandes (2017); Nodari e Lima (2017), entre outras, que demonstram o impacto positivo da aplicação do PNAES e da Lei de Cotas aqueles a quem se destinam.

$\mathrm{Na}$ Universidade pesquisada os estudantes podem ingressar através de oito cotas, sendo elas (UFSM, 2020a, grifos próprios):

Cota L1 - Candidatos que tenham cursado integralmente o Ensino Médio em escolas públicas com renda bruta familiar por pessoa igual ou inferior a 1,5 salário-mínimo.

Cota L2 - Candidatos que tenham cursado integralmente o Ensino Médio em escolas públicas com renda bruta familiar por pessoa igual ou inferior a 1,5 salário mínimo autodeclarados pretos, pardos ou indígenas.

Cota L5 - Candidatos que tenham cursado integralmente o Ensino Médio em escolas públicas com renda bruta familiar por pessoa superior a 1,5 salário mínimo.

Cota L6 - Candidatos que tenham cursado integralmente o Ensino Médio em escolas públicas com renda bruta familiar por pessoa superior a 1,5 salário mínimo autodeclarados pretos, pardos ou indígenas. 
Cota L9 - Candidatos com deficiência (que se enquadre no Decreto Federal $n^{\text {o }} 3.298$, de 20/12/1999 e na Recomendação $n^{\circ} 03$ de 01/12/2012) que apresente necessidade educacional especial e que tenham cursado integralmente o Ensino Médio em escolas públicas com renda bruta familiar por pessoa igual ou inferior a 1,5 salário-mínimo.

Cota L10 - Candidatos com deficiência (que se enquadre no Decreto Federal no 3.298, de 20/12/1999 e na Recomendação no 03 de 01/12/2012) que apresente necessidade educacional especial e que tenham cursado integralmente o Ensino Médio em escolas públicas com renda bruta familiar por pessoa igual ou inferior a 1,5 salário-mínimo autodeclarados pretos, pardos ou indígenas.

Cota L13 - Candidatos com deficiência (que se enquadre no Decreto Federal n ${ }^{\circ} 3.298$, de 20/12/1999 e na Recomendação no 03 de 01/12/2012) que apresente necessidade educacional especial e que tenham cursado integralmente o Ensino Médio em escolas públicas com renda bruta familiar por pessoa superior a 1,5 salário mínimo.

Cota L14 - Candidatos com deficiência (que se enquadre no Decreto Federal no 3.298, de 20/12/1999 e na Recomendação no 03 de 01/12/2012) que apresente necessidade educacional especial e que tenham cursado integralmente o Ensino Médio em escolas públicas com renda bruta familiar por pessoa superior a 1,5 salário mínimo autodeclarados pretos, pardos ou indígenas.

A pesquisa de Mattos e Fernandes (2019) aponta que mesmo com essas políticas implementadas, isso não é o suficiente. Muitos estudantes ainda necessitam procurar por atividades extras que os remunerem, entre estágios, bolsas acadêmicas, trabalhos formais e informais. Levantamos a hipótese que questões como essas podem ocasionar evasão por dificuldade em conciliar os estudos com o trabalho.

Os recursos financeiros destinados à Educação, que já vinham sendo cortados, foram ainda mais impactados: desde 2019 , houve redução de $25 \%$ do valor destinado ao referido fim (OLIVEIRA, 2021). Esses cortes afetam, de forma acentuada, os estudantes beneficiários dessas políticas, uma vez que isso reflete diretamente na assistência estudantil (UFSM, 2020b.), visto que haverá a necessidade de reestruturação em aspectos relacionados as novas demandas de segurança para o retorno das atividades presenciais se adequarem ao "novo normal".

A ANDIFES (Associação Nacional dos Dirigentes da Instituições Federias de Ensino Superior) ainda prevê um aumento na demanda por essas políticas, ocasionadas pelo impacto socioeconômico ocorrido devido à pandemia da COVID-19 (UFSM, 2020b). De acordo com as informações, a Associação está desenvolvendo estudos com detalhamentos acerca desse impacto de novos recursos financeiros, para ser apresentado ao Congresso Nacional.

Além da legislação que discorremos, de acesso e permanência, em 2010 houve a implementação do Sistema de Seleção Unificada (SISU), aumentando as possibilidades 
dos estudantes que realizem o ENEM (Exame Nacional do Ensino Médio) ingressem em universidades de outras cidades e estados. De acordo com Li (2016), após a adesão do SISU houve aumento de matrículas de estudantes interestaduais. Os dados de Rodrigues (2016) indicam que as matrículas de estudantes de escola pública e de estudantes de baixa renda também elevaram.

Com o aumento de estudantes de escola pública e de baixa renda, bem como o aumento de matrículas interestaduais, levanta-se à suspeita do aumento da demanda de estudantes pelo PNAES, porém não foi possível encontrar dados que confirmassem ou negassem tal hipótese.

Para Lima (2019), o PNAES é fundamental, e proporciona "maior equidade de oportunidades na tentativa de eliminar possíveis dificuldades que se sobrevenham durante o desenvolvimento acadêmico, contribuindo para a melhoria do desempenho" (LIMA, 2019, p. 14). Os dados da pesquisa ainda indicam a forma significativa que esse ambiente possui na permanência dos assistidos dentro da Instituição pesquisada.

As bolsas acadêmicas, por vezes, são as mais favoráveis para os estudantes que necessitam de renda extra, uma vez que, de forma geral, possibilitam a conciliação do horário de atividades com os das aulas.

Na pesquisa de Nunes e Veloso (2017) é demonstrado como a escassez de bolsas acadêmicas e de estágios acabam favorecendo os estudantes com melhor desempenho acadêmico, deixando de fora os que mais necessitaram destas economicamente. Subentende-se que àqueles com melhor desempenho acadêmico são os que possuem disponibilidade para se dedicar integralmente aos estudos, e não os que precisam exercer atividades laborais para seu sustento ou de terceiros.

Quanto ao baixo rendimento acadêmico, alguns dos entrevistados da pesquisa de Lima (2019) justificam pela falta de apoio pedagógico e psicológico, enquanto os dados de Mattos e Fernandes (2019) indicam a falta de apoio pedagógico. Mesmo que tais apoios sejam previstos pelo PNAES.

A defasagem da qualidade de ensino, que muitas vezes ocorre nas escolas públicas, é relatada como um dos principais dificultadores na transição do ensino médio para o ensino superior, segundo uma das entrevistadas de Mattos e Fernandes (2019). Os dados apontam não somente a questão de conteúdo acadêmico, mas também em relação a apresentação de trabalhos e ao pensamento crítico, bem como estar aberta a discutir tais pensamentos. 
Além de desafios acadêmicos e instituicionais, o ambiente universitário também demanda habilidades pessoais, interpessoais e, claro, científicas (MATTOS; FERNANDES, 2019). Como facilitadores de permanência, são apresentados a relação de proximidade com colegas e professores (SANTOS, 2018).

As pesquisas apresentadas evidenciam a importância das políticas de acesso e permanência e dos demais programas de assistência estudantil, bem como a necessidade dos estudantes de buscarem por meios complementares a fim de se manterem dentro do curso.

Nesse contexto, surge a necessidade de verificar as políticas de assistência estudantil e como essas vêm ocorrendo. Assim, estabeleceu-se como objetivo conhecer as políticas de assistência estudantil existentes dentro de uma Universidade Federal (UF) brasileira, assim como analisar a percepção dos estudantes sobre a importância dessas para a sua formação.

\section{METODOLOGIA}

Trata-se de uma pesquisa básica, de natureza descritiva. A abordagem utilizada é o estudo de caso e os dados foram analisados de forma qualitativa.

O estudo qualitativo considera a relação do sujeito com o mundo, considerando que são subjetivas e pessoais demais para que sejam quantificadas (MINAYO; DESLANDES; GOMES. 2009). E o estudo de caso, de acordo com Gil, "é caracterizado pelo estudo profundo e exaustivo de um ou de poucos objetos, de maneira a permitir seu conhecimento amplo e detalhado" (2008, p. 76).

Para a coleta de dados foi utilizado um questionário online, através do Google Forms e pesquisas no site da Instituição. O formulário foi composto por 14 perguntas, divididas em duas categorias: identificação do participante e políticas de assistência estudantil.

$\mathrm{Na}$ primeira categoria, o estudante deveria preencher dados pessoais básicos; a segunda foi sobre o que conhecia da assistência estudantil, e/ou e quais utilizava, as opções de resposta eram com base no que é proposto pelo PNAES (BRASIL, 2010). Assim, o questionário tinha questões como: Você ingressou utilizando alguma cota? Qual? Você sabe o que são as políticas de assistência estudantil?; Você já utilizou ou utiliza alguma política de assistência estudantil? 
Para o envio do formulário aos participantes, houve contato, através de e-mail, com as coordenações dos cursos do Centro pesquisado sendo solicitado que fosse repassado aos estudantes com matriculas ativas. O formulário ficou disponível de 09/10/2020 à 01/11/2020. O consentimento foi presumido aos participantes que decidiram dar sequência e finalização do formulário.

O presente artigo, bem como o trabalho de qual foi originado, está vinculado ao projeto internacional intitulado de Acessibilidade e inclusão em contextos universitários diferenciados, vinculado às demandas do Comité Académico Accesibilidad y Discapacidad da Asociación de Universidades Grupo Montevideo (AUGM), sob coordenação da Prof. a Dr. ${ }^{a}$ Sandra Eli Sartoreto de Oliveira Martins (UNESP). O Projeto foi enviado ao Comitê de Ética da Faculdade de Filosofia e Ciências/UNESP Marília, estando o mesmo em consonância com a Resolução de Pesquisa com Seres Humanos (CNS, 2012).

A busca no site da Universidade se deu entre novembro de 2020 e fevereiro de 2021. Acessando as páginas do próprio Centro pesquisado, da Pró-Reitoria de Assuntos Estudantis (PRAE), Coordenadoria de Ações Educacionais (CAED), entre outros. Destaca-se aqui, a dificuldade no acesso de informações, já que não estão unificadas e nem interligadas umas às outras.

Para a pesquisa, estava previsto, além do questionário, entrevistas presenciais com uma amostra dos estudantes que respondessem ao questionário. Porém, devido ao isolamento social imposto pela pandemia da COVID-19 (anos de 2020 e 2021), que limitou as atividades presenciais na Universidade pesquisada, optou-se, com base em Gil (2008), por apresentar apenas os dados do questionário, visto que apontavam dados suficientes para uma discussão ampla acerca do objetivo proposto.

Nesse sentido, Gil (2008, p. 140) nos aponta que o questionário “[...] consiste basicamente em traduzir objetivos da pesquisa em questões específicas". Após essa "tradução" foram obtidos os dados a respeito do público pesquisado. Segundo o autor, entre as vantagens desse tipo de coleta, estão a possibilidade de atingir um maior número de pessoas e a comodidade de que os participantes respondam quando quiserem.

Os participantes desta pesquisa foram estudantes de graduação de cursos presenciais de um centro de ensino, localizado no campus sede da Universidade pesquisada. O Centro conta com oito cursos de graduação presenciais e a distância, 
sendo todos eles de licenciaturas, além de quatro cursos de pós-graduação de lato sensu e stricto sensu.

Em setembro de 2020, haviam 1.045 matrículas ativas, e participaram dessa pesquisa 45 estudantes. Mesmo com o número reduzido de participantes, considera-se que o objetivo foi atingido, visto que conseguimos conhecer amplamente as políticas de assistência estudantis presentes na UF.

\section{RESULTADOS E DISCUSSÃO DE DADOS}

\section{Quanto ao perfil dos participantes:}

Das respostas obtidas, $93 \%$ pessoas se declararam do sexo feminino e os outros 7\% do sexo masculino (nenhum dos participantes marcou a opção "prefiro não informar").

Acredita-se que essa disparidade de respostas entre os sexos deve-se, ao fato que as mulheres ainda são a maioria nos cursos de licenciaturas. Segundo os dados do Censo da Educação Superior, divulgados pelo Instituto Nacional de Estudos e Pesquisas Educacionais Anísio Teixeira (INEP), as mulheres correspondiam à $72.2 \%$ dentro dos cursos de licenciatura do país (INEP, 2019a).

A idade dos participantes variou entre 18 e 46 anos. Sendo que $40 \%$ dos participantes estavam entre 18 a 20 anos de idade, configurando-se como a maior faixa etária dos participantes. Nas instituições de ensino superior do Brasil, esse grupo corresponde a $20 \%$, enquanto o maior percentual está entre os estudantes de idade entre 21 a 24 anos que ocupam 32\% das matrículas, entre públicas e privadas (INEP, 2019b).

A segunda maior participação foi dos estudantes entre 21 e 25 anos, com $38 \%$ de respostas. Seguidos de $13 \%$ entre os participantes de 31 a 43 anos e, por último, participantes entre 26 a 30 anos com $9 \%$.

O Centro pesquisado possui cinco cursos de graduação, sendo três deles diurnos e dois noturnos. Um dos cursos diurnos não teve nenhum participante. Como o contato foi através das coordenações dos cursos, levantamos a hipótese de que o convite para participar da pesquisa não chegou até os acadêmicos.

Entre os participantes, $46 \%$ utilizaram algum dos tipos de cota. Os outros 54\% ingressaram por ampla concorrência. A cota com mais incidência foi a Cota L5 - escola pública, independente de renda, instituída pela Lei 12.711 (BRASIL, 2012) de agosto de 2012. 
Em 2019, o Centro pesquisado contava com 15 matrículas regulares de estudantes que ingressaram pela reserva de vagas de estudantes com deficiência (UFSM, 2019a), instituía pela Lei no 13.409 de 2016 (BRASIL, 2016). Infelizmente, não houve participação de nenhum desses estudantes na pesquisa.

O perfil dos participantes é marcado por jovens mulheres, onde a maioria ingressou por ampla concorrência. Além das mulheres ainda ocuparem maior espaço dentro dos cursos de licenciatura, os dados de Savian (2018, p. 80) indicam a idade como um "fator de risco para a evasão" dentro da maioria dos centros investigados. Além disso, a pesquisadora ainda aponta que, de forma geral, os discentes da Instituição ingressam através da ampla concorrência e, somente 3,7\% utilizando cotas raciais ou de pessoa com deficiência.

\section{POLÍTICAS DE ASSISTÊNCIA ESTUDANTIL}

Os estudantes de baixa renda da Universidade podem contar com a assistência estudantil através do Benefício Socioeconômico (BSE). O edital é lançado no início de cada semestre, e são solicitados diferentes tipos de documentações voltadas para os dados socioeconômicos, a fim de que seja comprovada a necessidade do Benefício.

Há ainda critérios que devem ser atingidos em relação a situação acadêmica do estudante, para que o Benefício seja mantido, como aprovação em mais de 50\% das disciplinas matriculadas e carga horária mínima de 240h por semestre (UFSM, 2015a). O BSE abrange desde o ensino médio até a pós-graduação, essa última com critérios diferenciados, uma vez que o recurso vem direto da própria Instituição, e não do PNAES que contempla apenas cursos de graduação.

Os programas ofertados pela Universidade são: moradia, alimentação, auxílio transporte, auxílio material pedagógico, bolsas, acompanhamento psicossocial e atendimento odontológico (UFSM, 2019b), além de lavanderia coletiva para uso dos moradores, com agendamento prévio. Em 2019, $20 \%$ dos estudantes da Universidade eram beneficiários de algum dos tipos de assistência estudantil (UFSM, 2019b).

A Universidade conta com o total de seis moradias estudantis, denominadas de Casa do Estudante Universitário (CEU): quatro no campus da cidade sede, sendo uma específica para a pós-graduação e uma indígena; e duas localizadas em outros dois campi. 
As moradias são apartamentos que abrigam, geralmente, de dois até oito estudantes. $\mathrm{Na}$ cidade sede, a Instituição ainda conta com um bloco de apartamentos destinados à estudantes menores de idade, e alojamento provisório para os estudantes que aguardam aprovação do BSE, denominada de União Universitária. Estima-se que o total de vagas na moradia provisória seja de 180 (UFSM, 2021a), 2400² nos apartamentos da graduação/ensino médio e $83^{3}$ vagas nas moradias da pós-graduação.

Cabe destacar que a moradia estudantil passou a ter as suas primeiras instalações em 1963 (UFSM, 2008), muito antes do PNAES, que foi decretado em 2010. E, mesmo com um admirável número de vagas, situações como falta destas e de estruturas irregulares costumam ser presentes (VENTURINI, 2017), além da falta de acessibilidade interna para chegar até aos apartamentos ou até mesmo dentro destes.

Dos participantes da pesquisa, $80 \%$ responderam de forma afirmativa sobre saber o que são as políticas de assistência estudantil e $20 \%$ participantes não tinham certeza. Entre eles, 69\% responderam que utilizam algum tipo de assistência estudantil, enquanto $13 \%$ não têm certeza e $18 \%$ não utilizam. Como demonstrado no gráfico abaixo:

Gráfico 01 - Conhecimento e utilização de políticas de assistência estudantil.

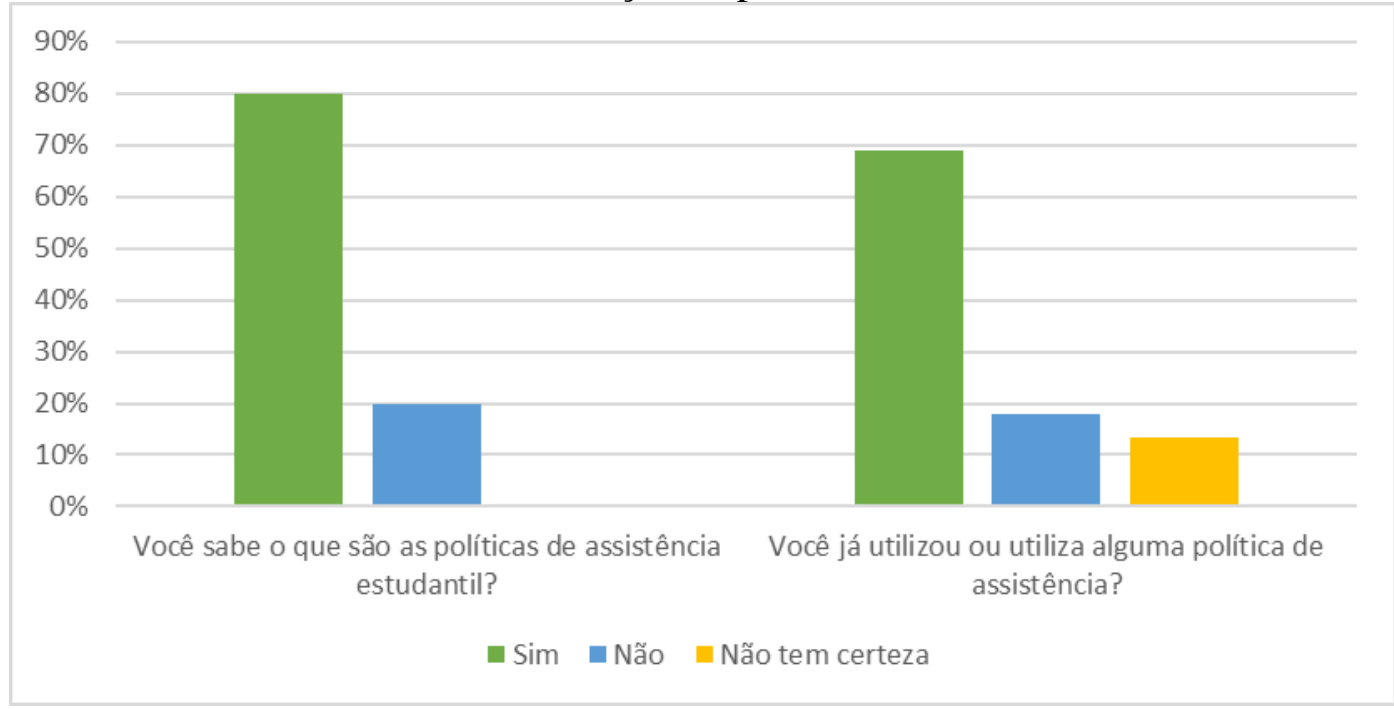

Fonte: dados da pesquisa, 2020.

\footnotetext{
${ }^{2}$ Dado fornecido por servidor da PRAE via e-mail em 04/01/2021.

${ }^{3}$ Ibidem.
} 
Quando os tipos de assistência, citados no parágrafo primeiro do Art. $3^{\circ}$ do PNAES (BRASIL, 2010), são dispostos como opções de respostas, 27\% dos participantes responderam não utilizar nenhuma.

Se comparados, o Gráfico 1 - Conhecimento e utilização de políticas de assistência estudantil e o Gráfico 2 - Utilização de meios de assistência estudantil, é possível perceber um aumento de $9 \%$ de participantes que consideram não usar meios de assistência estudantil. Levantando a hipótese de que esse $9 \%$ não sabiam exatamente quais seriam os tipos de assistência estudantil.

As opções de respostas são descritas no PNAES (BRASIL, 2010), conforme segue no gráfico abaixo:

Gráfico 02 - Utilização de meios de assistência estudantil.

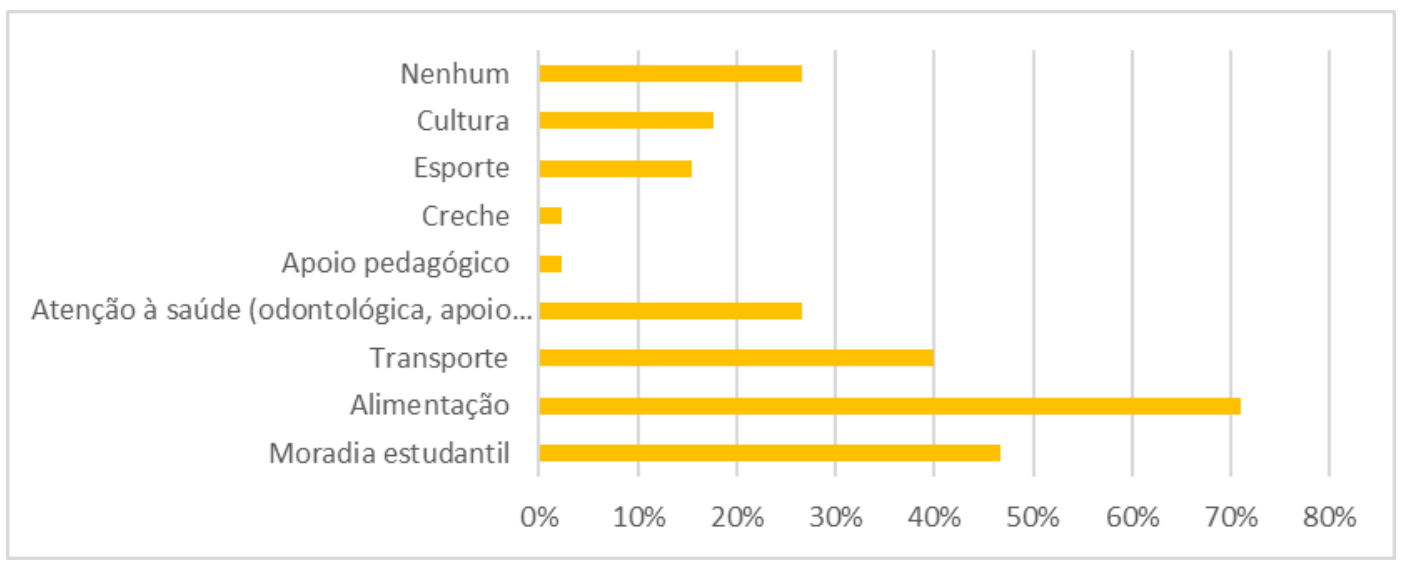

Fonte: dados da pesquisa, 2020.

A alimentação foi o item mais selecionado pelos participantes, sendo mencionado 71,1\% das vezes. Na Instituição, os beneficiários da assistência estudantil pelo BSE possuem as três refeições (café, almoço e janta) de forma gratuita.

A última pergunta da categoria, reflete sobre a importância da assistência estudantil para os assistidos. Dos $74 \%$ participantes que utilizam algum tipo de assistência estudantil, 82\% deles assinalaram não conseguir dar continuidade na trajetória acadêmica sem essa assistência.

Os dados de Lima (2019) demonstram sobre a relevância da moradia estudantil como meio de estar e permanecer no ensino superior. Assim como os dados de Savian (2018) que indicam um baixo índice de evasão entre os moradores das CEUs, estudantes que tinham acesso à alimentação dentro da Universidade, e que estão 
inseridos em projetos acadêmicos e bolsas. Indicando, assim, que tais fatores influenciam de forma positiva na permanência dos acadêmicos.

Abordando ações voltadas para a assistência estudantil no período de pandemia (2020-2021), onde a Instituição está com aulas remotas via REDE (Regime de Exercícios Domiciliares Especiais), mantiveram-se os atendimentos psicológicos através de órgãos internos da Universidade, em formato remoto.

Ademais, a fim de minimizar as barreiras de aprendizagem, foram lançados alguns editais, destacam-se: auxílio inclusão digital objetivando "fornecer recursos financeiros para aquisição de plano de internet/dados móveis" (UFSM, 2020c); e auxílio inclusão digital - aquisição de equipamento que "tencionava prover recursos financeiros para aquisição de computador ou tablet" (UFSM, 2020d) e o projeto alunos conectados que visava a "cessão de chip novo de telefonia celular com pacote de dados móveis do Serviço Móvel Pessoal" (UFSM, 2020e). Os dois últimos eram de valores préestabelecidos de acordo com os editais, sendo que os três eram destinados aos estudantes com BSE ativo.

\section{CONSIDERAÇÕES FINAIS}

Utilizando-se de um conceito mais amplo de inclusão, os dados aqui apresentados referem-se aos estudantes em situação de vulnerabilidade socioeconômica no Ensino Superior, visto que esse público compõe 70,2\% dos estudantes da Instituição (ANDIFES, 2018) e que, até mesmo por isso, a Universidade pesquisada é considerada como "uma das maiores assistências estudantis da América Latina" (UFSM, 2019e) pelo tamanho de sua abrangência.

Diante dos objetivos propostos, relacionados diretamente à assistência estudantil, foi possível reconhecer a existência destas, bem como identificar quais são e que vão de encontro ao que é proposto pelo PNAES. Devido à falta de participação por parte dos estudantes com deficiência, não foi possível inferir sobre como as políticas de assistência estudantil acontecem para este público.

Os participantes evidenciam a importância da assistência estudantil para a sua formação, onde a maioria indica que não poderiam prosseguir com os estudos sem estas. Pelos estudantes, houve destaque na utilização de moradia estudantil e a alimentação, que são indicados como itens que corroboram para a baixa evasão (SAVIAN, 2018). 
O Centro pesquisado teve uma alta de $7,76 \%$ em sua taxa de evasão, entre o ano de 2016 e 2018 (UFSM, 2019f). Ainda assim, de acordo com Savian (2018), o índice de evasão do Centro pesquisado estava entre os menores quando comparado aos demais centros da Instituição pesquisada.

Acredita-se que, entre os fatores, podem estar a falta de conhecimento sobre as políticas e ações existentes que buscam garantizar a permanência na Instituição, bem como a falta de manutenção, investimento e recursos públicos. Indicando, assim, a importância de recursos governamentais, bem como a divulgação por parte da Instituição e Centro de Ensino.

Como referenciado por um dos entrevistados na pesquisa de Saldanha, Costa e Castro (2019, p. 198):

[...] tem a cota, a gente coloca o estudante dentro da graduação [...] só que vai chegar lá na frente e vai ver quantos se formaram, pouquíssimos concluíram, porque dentro da graduação, da sua vivência aqui, não tiveram políticas públicas e políticas de assistência estudantil efetivas que garantissem a permanência do indivíduo [...]

É necessário que as políticas públicas e políticas de assistência estudantil sejam efetivas, e que oportunizem a permanência dos estudantes, para que estes se formem enquanto profissionais na carreira que escolheram, além de amplamente divulgadas. Reitera-se, assim, a importância de prosseguir com investigações sobre o desenvolvimento de ações afirmativas dentro das Instituições de Ensino Superior.

\section{REFERÊNCIAS}

BOOTH, Tony. AINSCOW, Mel. Índice de inclusión: Desarrollando el aprendizaje y la participación en las escuelas. UNESCO - Oficina Regional de Educación para América Latina y el Caribe, 2002.

BRASIL. DECRETO N $\mathbf{N}^{\mathbf{7}}$ 7.234, DE 19 DE JULHO DE 2010. Dispõe sobre o Programa Nacional de Assistência Estudantil - PNAES. Disponível em: < http://www.planalto.gov.br/ccivil_03/_ato2007-2010/2010/decreto/d7234.htm>. Acesso em 07 de ago. de 2020.

BRASIL. LEI No 12.711, DE 29 DE AGOSTO DE 2012. Dispõe sobre o ingresso nas universidades federais e nas instituições federais de ensino técnico de nível médio e dá outras providências. Brasília, DF, ago. 2012. Disponível em: <http://www.planalto.gov.br/ccivil_03/_ato2011-2014/2012/lei/112711.htm>. Acesso em: 07 de ago. de 2020.

BRASIL. LEI N'13.409, DE 28 DE DEZEMBRO DE 2016. Altera a Lei $n^{\circ} 12.711$, de 29 de agosto de 2012, para dispor sobre a reserva de vagas para pessoas com deficiência 
nos cursos técnico de nível médio e superior das instituições federais de ensino. Disponível em: <http://www.planalto.gov.br/ccivil_03/_ato20152018/2016/lei/113409.htm>. Acesso em: 07 de ago. de 2020.

BRASIL. Ministério da Educação. Étnico-racial. Brasília, 2020. Disponível em: <http://etnicoracial.mec.gov.br/acoes-afirmativas〉. Acesso em: 07 de ago. de 2020.

FALCÃO, Felipe Duclos Carisio. et al. Educação Inclusiva na UERJ: O Ingresso de Alunos com Necessidades Educacionais Especiais no Ensino Superior - Uma Prática em Construção. In: ALMEIDA, Maria Amelia, MENDES, Enicéia Gonçalves e HAYASHI, Maria Cristina Piumbato Innocentini. Temas em Educação Especial: Múltiplos Olhares. Araraquara: Junqueira\&Marin, 2008. p. 212 - 219.

GIL, Antônio Carlos. Métodos e técnicas de pesquisa social. 6. ed. São Paulo: Atlas, 2008. $220 \mathrm{p}$.

INSTITUTO NACIONAL DE ESTUDOS E PESQUISAS EDUCACIONAIS ANÍSIO TEIXEIRA. Senso da Educação Superior. Notas Estatísticas 2019. Brasília: Inep, 2020a.

INSTITUTO NACIONAL DE ESTUDOS E PESQUISAS EDUCACIONAIS ANÍSIO TEIXEIRA. Sinopse Estatística da Educação Superior 2019. Brasília: Inep, 2020b.

LI, Denise Leyi. O Novo ENEM e a plataforma SiSU: efeitos sobre a migração e a evasão estudantil. 2016. 108 f. Dissertação (Mestrado em Ciências) - Faculdade de Economia, Administração e Contabilidade, Universidade de São Paulo, São Paulo, 2016.

LIMA, Fábio Danilo Rolim de. A política pública de assistência estudantil: uma análise sobre a contribuição do benefício da residência universitária para a permanência na UFPB. 2018. 114p. Dissertação (Mestrado Profissional) - Universidade Federal da Paraíba, João Pessoa, 2018.

MATTOS, Hellen Cristina Xavier da Silva. FERNANDES, Maria Cristina da Silveira Galan. Estudantes universitários: estratégias e procedimentos para a permanência. Revista Contemporânea de Educação, Rio de Janeiro, v 14, n. 29, p, 156-174, jan/abril, 2019.

MINAYO, Maria cecilia. DESLANDES, Suely Ferreira. GOMES, Romeu. Pesquisa social: teoria, método e criatividade. 25. ed. rev. atual. Petrópolis: Vozes, 2007. 108p.

NUNES, Roseli Souza dos Reis; VELOSO, Tereza Christina Mertens Aguiar. Desafios da permanência para estudantes com vulnerabilidades socioeconômicas no contexto da educação superior pública. In: SEMINÁRIO NACIONAL DA REDE UNIVERSITAS, XXV, 2017, Brasília. Anais [recurso eletrônico] Brasília/DF: Faculdade de Educação, UnB, 2017, p. 1-24.

OLIVEIRA, Elida. Corte de mais de $18 \%$ no orçamento das universidades federais em 2021 poderá inviabilizar ensino, diz entidade. G1, São Paulo, 18 de mar. 2021. Disponível em: <https://g1.globo.com/educacao/noticia/2021/03/18/corte-de-mais-de- 
18percent-no-orcamento-das-universidades-federais-em-2021-podera-inviabilizarensino-diz-entidade.ghtml >. Acesso em: 26 de abr. de 2021.

RODRIGUES, Aline Xisto. Políticas Públicas de Acesso ao Ensino Superior: os resultados do SISU na Universidade Federal de Viçosa. 2016. 70f. Trabalho de Conclusão Final (Programa de Pós Graduação em Administração Pública em Rede Nacional) - Universidade Federal de Viçosa, Floresta, 2016.

SALDANHA, Luciléia Bechmann. COSTA, Tiane Pumes. CASTRO, Sabrina Fernandes de. Acessibilidade como um viés de permanência de acadêmicos com deficiência no ensino superior: estudo de caso de uma biblioteca universitária. In: Promoção da aprendizagem e tecnologia educacionais: aprendizagem no ensino superior, acessibilidade e ações afirmativas. Santa Maria: FACOS - UFSM, 2019, p. $190-201$.

SANTOS, Isabela Samogim. Processos de resiliência em universitários com deficiência. 2018. 122 f. Dissertação (Mestrado em Educação) - Universidade do Oeste Paulista, Presidente Prudente, 2018.

SAVIAN, Mônica Cristina Bogoni. Estudo dos fatores de risco associados à evasão de alunos de graduação da Universidade Federal de Santa Maria. 2018. 92 f. Dissertação (Engenharia de Produção) - Universidade Federal de Santa Maria, Santa Maria, 2018.

UNIVERSIDADE FEDERAL DE SANTA MARIA. Andifes alerta sobre impactos do corte no orçamento das IFES para Assistência Estudantil. Santa Maria, 2020b. Disponível em: <https://www.ufsm.br/2020/08/12/andifes-alerta-sobre-impactos-docorte-no-orcamento-das-ifes-para-assistencia-estudantil/>. Acesso em: 12 de jan. 2021.

UNIVERSIDADE FEDERAL DE SANTA MARIA. Centro de Educação. Comissão de Avaliação Institucional. Relatório final. Pesquisa GAP N. 051949. Indicadores de qualidade do Centro de Educação da UFSM. A evasão por abandono - 2012-2018. Santa Maria, 2019f.

UNIVERSIDADE FEDERAL DE SANTA MARIA. Coordenadoria de Ações Educacionais. Relatório Núcleo de Acessibilidade, 2019. Santa Maria, 2019a. Disponível em: https://www.ufsm.br/app/uploads/sites/391/2020/03/Relat\%C3\%B3rio2019NA_FINA>. Acesso em: 19 de nov. 2020.

UNIVERSIDADE FEDERAL DE SANTA MARIA. Edital $\mathbf{n}^{\mathbf{0}} \mathbf{0 2 0 / 2 0 2 0}$ PROGRAD, processo seletivo SISU/UFSM 2/2020. Santa Maria, 16 de jul. 2020a. Disponível em: <https://www.ufsm.br/app/uploads/sites/501/2020/07/Edital-ChamadaRegular-SiSUUFSM-Segunda-Edi\%C3\%A7\%C3\%A3o-de-2020.pdf $>$. Acesso em: 13 de jan. de 2021.

UNIVERSIDADE FEDERAL DE SANTA MARIA. Edital para o auxílio inclusão digital - PRAE $\mathbf{N}^{\mathbf{0}}$ 027/2020 - $\mathbf{1}^{\mathbf{0}}$ semestre de 2020. Santa Maria, 16 de jun. 2020c. Disponível em em: <https://www.ufsm.br/app/uploads/sites/347/2020/06/2020.06.16 Edital-027-2020- prae_-Aux\%C3\%ADlio-Inclus\%.pdf>. Acesso em 22 de jan. 2021. 
UNIVERSIDADE FEDERAL DE SANTA MARIA. Edital para o auxílio inclusão digital - aquisição de equipamento PRAE $\mathbf{N}^{\circ}$ 041/2020 - $2^{\circ}$ semestre de 2020. Santa Maria, 17 de set. 2020d. Disponível em: $<$ https://www.ufsm.br/app/uploads/2020/09/Edital-Auxilio-Inclusao-Digital-Aquisicaode-Equipamentos.pdf>. Acesso em 22 de jan. 2021.

UNIVERSIDADE FEDERAL DE SANTA MARIA. Edital para o projeto alunos conectados (RNP/MEC) - chip com pacote de dados móveis PRAE $n^{0}$ 048/2020 $2^{\circ}$ semestre de 2020. Santa Maria, 18 de nov. 2020e. disponível em: <https://www.ufsm.br/app/uploads/2020/11/Edital-Alunos-Conectados.pdf>. Acesso em 22 de jan. 2021.

UNIVERSIDADE FEDERL DE SANTA MARIA. PRAE recepciona novos moradores da Casa do Estudante em seminário integrador. Santa Maria, 2019e. Disponível em: <https://www.ufsm.br/2019/08/06/prae-recepciona-novos-moradoresda-casa-do-estudante-em-seminario-integrador/ >. Acesso em: 13 de jan. de 2021.

UNIVERSIDADE FEDERAL DE SANTA MARIA. Pró-Reitoria de Assuntos Estudantis. Santa Maria, 2021a. Disponível em: <https://www.ufsm.br/proreitorias/prae/moradias/>. Acesso em: 13 de jan. 2021.

UNIVERSIDADE FEDERAL DE SANTA MARIA. Pró-Reitoria de Assuntos Estudantis. Casa do Estudante. Santa Maria, 2008. Disponível em: < https://www.ufsm.br/proreitorias/prae/ceu/historia-da-casa/>. Acesso em: 13 de jan. de 2021.

UNIVERSIDADE FEDERAL DE SANTA MARIA. Referência no Brasil, assistência estudantil da UFSM pode ser comprometida por contingenciamento. Disponível em: < https://www.ufsm.br/2019/07/30/referencia-no-brasil-assistencia-estudantil-daufsm-pode-ser-comprometida-por-contingenciamento/> Santa Maria, 30 de jul. 2019b. Acesso em: 15 de jan. de 2021.

UNIVERSIDADE FEDERAL DE SANTA MARIA. Resolução N. 035/2015. Regulamenta o Programa de Benefício Socioeconômico no âmbito da Universidade Federal de Santa Maria, e revoga a Resolução n. 005/08. Santa Maria, 30 de dez. 2015a. Disponível em: <https://www.ufsm.br/app/2015.pdf>. Acesso em: 07 de fev. de 2021.

VARGAS, Hustana. HERINGER, Rosana. Políticas de permanência no ensino superior público em perspectiva comparada: Argentina, Brasil e Chile. Archivos Analíticos de Políticas Educativas, Arizona (EUA), v. 25, n. 72, p. 34, jul. 2017.

VENTURINI, Suellen. A vida na União Universitária. Diário de Santa Maria, Santa Maria, 26 de ago. 2017. Disponível em: < https://diariodesantamaria.atavist.com/avidana-uniao-universitaria-daufsm\#: :text=Os\%\%20>. Acesso em: 14 de jan. 2021. 